\title{
La "Ciudad de Dios" y la "Ciudad del hombre": convergencias y tensiones*
}

\section{PREÁMBULO}

El de las dos ciudades es un tema central en teología de la historia ${ }^{1}$. Relacionado con numerosas tesis del humanismo cristiano, de la filosofía y de la política, con hondas raíces bíblicas y teológicas, su estudio se hace especialmente necesario en nuestro tiempo "a fin de que la Iglesia-como el Concilio dijo- pueda responder con mayor plenitud a los peculiares condicionamientos del mundo actual" 2 . En campo agustiniano, es de los que mantienen más "vivo y atrayente el encanto de san Agustín ante la sociedad moderna" 3 , y en lo que al presente cursillo se refiere, programado como está bajo el lema del amor y justicia social en la espiritualidad agustiniana hoy, resulta, además de complementario, recapitulador y conclusivo. $\mathrm{Su}$ amplitud y dificultad saltan a la vista. Intentaré, por eso, ajustarme a los cánones de la escueta interpretación echando mano de la síntesis.

\section{LAS DOS CIUDADES}

1. Textos

San Agustín esboza la idea en De uera religione, última obra de laico, escrita en Tagaste hacia el 390. Entonces sólo con dos géneros de hombres

* Este artículo es la conferencia que el autor pronunció el 18 de noviembre de 1989 en el Aula Magna del Augustinianum, como clausura del congreso internacional de espiritualidad agustiniana celebrado en Roma aquellos días y que tuvo por título general Dio è amore é Dio.

1. Para un estudio orgánico del tema, cf. A. LAURAS-H. RonDET, Le thème des deux cités dans l'oeuvre de saint Augustin, en Études agustiniennes (Paris 1953), p. 97-160; A. LAURAs, Deux Cités, Jérusalem et Babylone: CDios 167 (1954) 117-150; A. MANDouze, Saint Augustin. L'aventure de la raison et de la grâce, (Paris 1968) p. 289-330; A. TrAPè, S. Agostino. L'uomo, il pastore, il mistico (Fossano 1976) p. 313-326; Id., Introduzione generale a la Città di Dio: Teologia (Roma, Città Nuova, 1978) p. LXIV-LXXI (bibl.: CLIII-CLXXXIII); Id., San Agustín, en Patrología III, BAC 422 (Madrid 1981) p. 434; V. CAPÁNAGA, Introducción a La Ciudad de Dios, BAC 171/XVI (Madrid 1977) p. 7-112: espec. 17-50.

2. LG 36, en Concilio Vaticano II, Constituciones. Decretos. Declaraciones, BAC 252 (Madrid 1967) p. 104.

3. Augustinum Hipponensem, prol. not. 6, en Toma y lee. San Agustín. XVI centenario de la conversión, PPC/FAE (Madrid 1986) p. 14. 
(ueterem atque terrenum / nouum uero et caelestem); con dos pueblos (pius populus / impius populus) ${ }^{4}$. Diez años más tarde, en De catechizandis rudibus, llegan al diseño las dos ciudades: duae itaque ciuitates, una iniquorum, altera sanctorum, ab initio generis humani usque in finem saeculi perducuntur ${ }^{5}$. También son incorporados entonces el nombre y el significado de cada una 6.

El horizonte se amplía pocos años después, en De genesi ad litteram libri $X I I$, con un texto de oro en el que existen no sólo expresamente escritos la noción y el fundamento, sino elencadas por menudo las tensiones y avanzada la promesa explícita de escribir la La Ciudad de Dios ${ }^{7}$. Las Enarrationes proporcionan al estudioso abundante material, especialmente In Ps. 61, 64, $86,136,138$ y 142 . Es verdad que su imprecisa cronología impide fijar el contexto, pero no concluir que en ellos figuran el objeto mismo (las dos ciudades), su fundamento (los dos amores), su historia (percepciones y consolaciones), sus manifestaciones (obras de caridad o de egoísmo) y el éxito o el fracaso finales (bienaventuranza o miseria) ${ }^{8}$.

Pero donde la idea alcanza madurez expositiva, rigor sistemático y densidad conceptual es en la Ciudad de Dios, admirable resumen del pensamiento filosófico, teológico y político de Agustín. Compuesta entre el 413 y el 426, su tesis capital es que la Providencia divina "ilumina y guía la historia de la humanidad, dividida en dos ciudades, nacidas de dos amores, el amor de sí y el amor de Dios" 9 .

\section{Fundamento bíblico}

Agustín encuentra el nombre y el contenido en las Sagradas Escrituras. Recuerda él mismo los textos que traen la expresión y hasta cita los Salmos 45,5-6; 47,2-3.9; y 86,3. Una vez interpretados en sentido místico, afirma: "Con estos y otros testimonios semejantes (...), sabemos que hay una ciudad de Dios, cuyos ciudadanos deseamos nosotros ser" ${ }^{10}$. Y en otra parte: "no

4. De u.rel. 27,50 (CC 32, 219s; BAC 30/IV, p. 128-131); A. TRAPÈ: BAC 422, p. 429.

5. De c.rud. 19,31 (CC 46, 156).

6. Ib. 21,37. (CC 46, 161). Véanse, A. Trapè: BAC 422, p. 443; A. LAURAs-H. Rondet, 104s; A. LAURAs, 119s; Y. Congar, Eclesiología. Desde san Agustín hasta nuestros días, en Historia de los Dogmas, Tomo III, Cuaderno 3c-d, BAC. Enciclopedias (Madrid 1976) p. 6.

7. Cf. De Gen. litt. XI, 15 (CSEL 28/1, 347s). A. LAURAS-H. RONDET, 112s; A. Trapè Introduzione generale, p. XII.

8. Cf. LAURAS-Rondet, 111-128; LAURAS, 123-133; TraPE, Introduzione, p. LXV.

9. TraPe: BAC 422, p. 431. Asimismo, LAURAS-RONDET, 138-152; LAURAS, 131s; CONGAR: BAC. Enciclopedias, 6s.

10. De ciu.Dei XI, 1 (CC 48, 231; BAC 171/XVI, p. 683). Utilizo la versión castellana de la BAC, pero reservándome la libertad de cambiar alguna palabra cuando lo juzgue necesario, que será pocas veces. 
existen más que dos clases de sociedades humanas, que podemos llamar justamente, según nuestras Escrituras, las dos ciudades" 11.

Las antítesis manejadas a menudo por Agustín en el entramado de las dos ciudades figuran, ciertamente, en la Escritura ${ }^{12}$. Por otra parte, la estructura de la Ciudad de Dios está levantada sobre la Biblia, y aunque es difícil apreciar brevemente los valores todos de su precisa y preciosa documentación, podemos destacar, junto a la resonancia profética, el valor exegético ${ }^{13}$.

Con el significado simbólico que la Escritura da a dichas ciudades y la interpretación agustiniana de sus nombres -Jerusalén (Visión de paz); Babilonia (Confusión) ${ }^{14}$, era obvio que entrasen ambas a formar parte de una terminología habitual y fuesen asumidas como la expresión de dos ciudades que ocupan y dominan la historia. Señalado papel hay que reservar, sobre todo, a san Pablo, pues cada uno de los conceptos aquí examinados tiene en sus cartas antecedente claro, preciso y directo ${ }^{15}$. Los especialistas, en fin, concuerdan en admitir esta base bíblica, pero discrepan al explicar cómo Agustín la sistematizó y qué autores pudieran haberle ayudado.

\section{Posibles influjos extrabíblicos}

Sostuvo en su día G. Combés el del maniqueísmo, lo que suscitó pareceres encontrados y una dura crítica de E. Gilson. Que los maniqueos entusiasmaron al retórico de Tagaste por las Escrituras, está ya fuera de duda; que algunas consideraciones habían circulado antes en la secta de Manes, también. Pero de ahí a concluir que en el análisis de la cuestión Agustín es deudor suyo media un abismo ${ }^{16}$.

11. De ciu. Dei XIV, 1 (CC 48, 414; BAC 172/XVII, p. 64). "La concezione delle due città opposte è attinta direttamente dalle Scritture del Nuovo Testamento", afirma A. Romeo citando en nota Mt 6,19-24; 12,25-45; 25,31-46; Io 1,10-13; 3,17-21; 15,18-16,11; cf. 1 Io 2,13-23; 5,1720 (cf. L'antitesi delle due città nella spiritualità di S. Agostino, en Sanctus Augustinus vitae spiritualis magister, I, Roma 1959, p. 120; A. TRAPE, Introduzione, LXV. Véanse también los estudios del apartado La Bible dans la Cité de Dieu, en A.-M. LA BonNARdièr, Saint Augustin et la Bible. Bible de tous les temps (Paris 1986) p. 359-398.

12. Cf. A.-M. LA BonNARdière, L'épître aux Hébreux dans l'euvre de saint Augustin: REAug 3 (1957) 137-162; B. QuINOT, L'influence de l'Epître aux Hébreux dans les oeuvres principales de saint Augustin, Diss. Greg. (Roma 1959).

13. Cf. A.-M. LA Bonnardière, On a dit de toi des choses glorieuses, Cité de Dieu!, en Saint Augustin et la Bible, 261-368: 364ss.

14. Cf. In Ps. 64,2; LAURAS-Rondet, 115; LAURAS, 132-136.

15. Cf. L. Cilleruelo, La oculta presencia del maniqueísmo en la "Ciudad de Dios" en Sanctus Augustinus vitae spiritualis magister, I, p. 475-509: 505; TRAPÈ, Introduzione, p. LXVs.

16. G. ComBÉs, La doctrine politique de Saint Augustin (Paris 1927) p. 36; E. GILSON, Introduction a l'étude de Saint Augustin (Paris 1943) p. 241. Al respecto, véanse A. Romeo, 120, not. 13; A. MANDOUzE, 302, not. 2, y P. DE Luis, Introducción general, BAC 487/XXX, Escritos antimaniqueos $\left(1^{\circ}\right)$, Madrid 1986, p. 161-163. 
Menos probable parece el de la escuela platónica ${ }^{17}$. De la Patrística; por el contrario, se han barajado, con desigual fortuna, los nombres de Orígenes, Lactancio, Ambrosio, Filón y Ticonio. En cuanto a los tres primeros, la cosa no pasa de alusiones. Filón, en cambio, ofrece más elementos, pero insuficientes para sacar la tesis de la filiación y coincidencias adelante ${ }^{18}$.

Caso aparte me parece Ticonio con su Comentario al Apocalipsis, donde se puede leer: Ecce duas ciuitates, unam Dei et unam diabuli... Hae duae ciuitates, una mundo et una desiderat servire Christo ${ }^{19}:$ ¿Conocía este texto Agustín al emprender su Ciudad de Dios? Difícil saberlo. Menciona de paso la obra en $D e$ d.chr. III,30,42, y la influencia, aunque tardía, parece probable. Nos consta que estimaba y usaba el Liber regularum, pero el problema de Ticonio, en todo caso, era otro, pues se refería no a las dos ciudades en sentido agustiniano, sino a la única Iglesia, considerada pura e ideal, a pesar de contener hipócritas. Problema exegético, en Ticonio; dogmático-moral, en Agustín. Y aunque la inspiración ticoniana se admitiese, tampoco pasaría nada: lo que en Ticonio es motivo, en Agustín se vuelve orquestación y sinfonía ${ }^{20}$.

El de las dos ciudades, resumiendo, viene a ser tema vertebral de la antropología y eclesiología agustinianas. Aparece pronto en los escritos, y va ganando en matices con el paso de los años, hasta desembocar en la exposición global, grandiosa y definitiva de la Ciudad de Dios. De raíz indudablemente bíblica, es, sin embargo, el Hiponense quien estimula su desarrollo hasta conseguir la madurez doctrinal del árbol teológico que todos conocemos. Los posibles préstamos extrabíblicos nunca rebasan lo superficial y anecdótico, ni tampoco restan, por consiguiente, originalidad.

\section{PRECISIONES TERMINOLÓGICAS}

Antes de pasar a las convergencias y tensiones, y en orden a su mejor comprensión, oportuno será que precise qué hemos de entender por ciudad de Dios, y qué por ciudad del hombre.

17. Cf. L. Cilleruelo, 495; A. TrAPE, Introduzione, p. XXVI; Id., Escatologia e antiplatonismo di S. Agostino: Aug. 18 (1978) 237-244.

18. Cf. H. ScHOLz, Glaube und Unglaube in der Weltgeschichte (Leipzig 1941) p. 77-80; L. Cilleruelo, 502-504; A. TRAPE, Introduzione, p. LXVI.

19. Comm in Apoc. fragm. 8,12 (PLS 1,650).

20. Cf. A. Trapè, Introduzione, p. LXVI. Además, Lauras-Rondet, 106; Cilleruelo, 504; E. ROMERo Pose, Et caelum ecclesia et terra ecclesia. Exégesis ticoniana de Apocalipsis 4,1: Aug. 19 (1979) 469-486; M. Dulaey, L'Apocalypse. Augustin et Tyconius. La Bible dans la Cité de Dieu, en Saint Augustin et la Bible, 369-386. Para más bibliografía ticoniana, P. LANGA, Aparato bibliográfico, BAC 498/XXXII (Madrid 1988) p. XXXVs. 


\section{Ciuitas}

Lo mismo que ecclesia denota, de entrada, el edificio donde los fieles se congregan, ciuitas, es, para empezar, el lugar de la vida cotidiana de los ciudadanos. En ambos casos, sin embargo, los muros delimitan un espacio, desde luego, pero distan de comprender una conjunto coherente. Una ciuitas christiana, siendo así, tiene poco sentido para el de Hipona, pues sugiere de pronto la idea de ecclesia como reunión o multitud, de la que el templo viene a ser su más transparente imagen. Pero ciuitas encierra en Agustín más riqueza conceptual; es otra cosa, algo superior a toda ciudad concreta. En sentido propio ciuitas es, por consiguiente, la unidad invisible constituida por un grupo de hombres que aspiran a un mismo fin, con un mismo corazón, y de un mismo amor enamorados ${ }^{21}$.

\section{Ciuitas Dei}

No es una institución o sociedad así designada, sino grandeza mística coexistente con el designio creacional de Dios, puesto que esta ciudad ha comenzado a existir antes de la creación del hombre ${ }^{22}$. La ciudad de Dios es, de suyo, esencialmente celestial; y los ángeles, sus primeros ciudadanos; y Dios, el Creador (conditor). Pero es preciso distinguir bien entre ciudad de Dios e Iglesia. Se tiende a identificarlas, cuando no son, exàctamente, la misma cosa. La Ecclesia de Agustín está más cerca de nuestro término comunidad, reemplazable, a su vez, por los de genus, populus, societas. Pero no es lo mismo que ciuitas Dei. De hecho, en los escritos agustinianos va frecuentemente acompañada de un determinativo: Ecclesia quae in hominibus est; o Ecclesia deorsum quae peregrinatur, etc. ${ }^{23}$.

Que existen textos donde Agustín toma una y otra como expresiones equivalentes, o pasa de un término a otro sin dificultad, conforme. En el Enchiridion, por ejemplo, la ciudad de Dios está propuesta en términos de

21. Cf. Civitas: ThLL III, 1229-1240; G. DEL EsTAL, J.J.R. RosADO, Equivalencia de civitas en el De Civitate Dei: CDios 167 (1965) 367-454; J.C. MANN Civitas. A further Comment: Antiquity 35 (1961) 142-143; la voz "civitas", en H.J. SIEBEN, Voces. Eine Bibliographie zu Wörtern und Begriffen aus der Patristik (1918-1978), Walter de Gruyter-Berlin 1980, p. 253.

22. Cf. De ciu.Dei XIV, 28 (CC 48,451).

23. Ench. 15,56 (CC 46,80); 15,56; In Ps. 136,1; 126,3; 149,5. Véanse, E. LAMIRANDE, L'Église céleste selon S. Augustin (Paris 1963) p. 88ss.; Y. CONGAR, "Civitas Dei" et "Ecclesia" chez saint Augustin: REAug 3 (1957) 1-14; Id.: BAC. Enciclopedias, 6s.; S. Folgado, Sentido eclesial católico de la "Civitas Dei". Puntos de eclesiología agustiniana: Aug. 14 (1974) 91-146 (reed. en S. FolgaDo, Dinamismo católico de la Iglesia en san Agustín, El Escorial 1977, p. 67133); MANDouZe, 297, not. 1; la expresión : civitas Dei", en H.H. SiEBEN, Voces, 253s. 
Iglesia ${ }^{24}$. Pero si el autor llama a menudo Iglesia a la parte celeste de la ciudad de Dios, nunca, casi nunca, dice de la ciudad de Dios que es mixta, ni le llama esposa de Cristo. Afirma, sí, que Cristo es la cabeza de los ángeles, pero no que éstos sean miembros del Cuerpo. Una identidad entre Iglesia de los santos, Cuerpo de Cristo y ciudad de Dios será posible siempre y cuando entendamos esa ciudad de Dios en el estado definitivo ${ }^{25}$. La ciudad de Dios en su dimensión escatológica, por tanto, es el reposo, la patria, lo que la vuelve objeto de nostalgia para el peregrino exiliado ${ }^{26}$; pero, repito, no es lo mismo que Iglesia.

\section{Ciuitas Dei-Ecclesia quae nunc est}

Agustín de Hipona afirma claramente que una parte de la ciudad de Dios todavía está en el destierro (peregrina), en donde, por lo demás, recibe ayuda de la parte celestial (opitulatur) ${ }^{27}$. Tal vez la distinción no sea fácil en algunos textos agustinianos de complicada hermenéutica, pero lo que se impone como incuestionable es que la Iglesia de los hombres -quae in hominibus est- ${ }^{28}$, o la ciudad de Dios en cuanto perteneciente a la humanidad -quantum ad hominum genus pertinet ${ }^{29}$-, se relaciona con Cristo no tanto porque él haya sido siempre caput Ecclesiae, o rex ciuitatis cuanto, más bien, por haber llegado a serlo con su encarnación y su pasión ${ }^{30}$.

Hay una ciudad de Dios, pues, en estado definitivo. Y otra, presente y obligada a medirse con las servidumbres y ritmos del tiempo. Dicho de otro modo: una ciudad de Dios en estado de travesía -también de crecimientollamada Iglesia, que "va peregrinando entre las persecuciones del mundo y los consuelos de Dios" 31. Ella es, precisamente, la ciudad de Dios peregrina, es decir, y para expresarlo con la famosa distinción agustiniana de la disputa antidonatista, la Ecclesia quae nunc est ${ }^{32}$.

24. Cf. Y. CongaR: BAC. Enciclopedias, 7.

25. Cf. Serm. Denis 16,7 (MA 1,80)=Serm. 299 D, 7 (BAC 448/XXV, p. 349).

26. Cf. In Ps. 61,7.

27. De ciu. Dei XVIII, 1 (CC 48, 598); Ench. 15,56 (CC 46, 79). Al respecto, E. LAMIRAN$\mathrm{DE}, L^{\prime}$ Église céleste, 125, 144ss.; Y. CoNGAR: BAC, Enciclopedias, 6.

28. Ench. 15, 56 (CC 46, 80).

29. De ciu. Dei XVIII, 1 (CC 48, 592).

30. Cf. Serm. 341, 11-12; Ench.16, 61.

31. LG 8 (Cf. De ciu. Dei XVIII, 52,2: BAC 252, p. 52).

32. Cf. Y. Congar, Introduction générale. Traités anti-donatistes I: BA 28 (Desclée de Brouwer 1963) 95-97; P. BORGOMEO, L'Église de ce temps dans la prédication de saint Augustin (Paris 1972) 303s; P. LANGA: BAC 498 (Madrịd 1988) 131-133. 


\section{Ciuitas diaboli-ciuitas terrena}

El principio de que no hay que confundir ciudad de Dios con Iglesia es asimismo predicable de la ciudad del diablo con la ciudad terrena, y, una vez aquí, de la ciudad terrena con Roma o el Estado ${ }^{33}$. Hay que reconocer, sin embargo, que la Iglesia da a los creyentes una idea de la ciudad de Dios, ya que la Iglesia no hemos de enjuiciarla sólo escatológicamente, como comunidad espiritual; es preciso verla también en su temporalidad, como Iglesia visible, sacramental e institucional, inseparable de la celeste, por ser, desde ahora, figura de la del cielo ${ }^{34}$.

De Roma y la ciudad terrena cabe decir otro tanto: Roma da a todos, paganos y cristianos, mejor que cualquier poder humano, una idea de la ciudad terrena, pues Agustín, cuando habla o escribe de una ciudad humana, piensa de pronto en la metrópoli del Imperio y en su historia, según había sido descrita por los escritores latinos, o sea, arruinada, llena de vicios, antes ya del nacimiento de Cristo y de la Iglesia ${ }^{35}$. Al escribir que dan una idea intento expresar una de las posibles y hasta mejores versiones del intraducible adverbio mystice, rico de significado y bastante más hondo que el de nuestro actual místico, según puede colegirse de una exégesis espiritual agrandada por las resonancias escriturísticas. Así parece aconsejarlo nuestro autor cuando escribe, por un lado: "...quas etiam mystice appellamus ciuitates duas..." 36; y por otro: "quas ciuitates duas secundum scripturas nostras merito appellare possemus" ${ }^{37}$.

33. Entre quienes han pretendido identificar la ciudad terrena con Roma, cumple mencionar a Maier y Gilson. En este mismo tema, y por reacción contra Kamlah, que había definido la ciudad de Dios como eschatologische Gemeinde, y que se había inclinado por la identificación del Imperio con la ciudad del diablo, Straub se fue por el camino inverso, esforzándose en probar que el imperio participa, en cierto sentido, de la ciudad de Dios. Véanse, F.G. MAIER, Augustin und das antike Rom (Tübinger Beiträge zur Altertumswissenschaft, vol. 39, Stuttgart 1955) 195; E. Gilson, Les métamorphoses de la Cité de Dieu (Louvain, Publications universitaires-Paris, Vrin, 1952) 54-55; W. KAMLAH, Christentum und Geschichtlichkeit. Untersuchungen zur Entstehung des Christentums und zu Augustins "Bürgerschaft Gottes" (Stuttgart-Köln 1951) 133-134; J. STRAUB, Augustins Sorge um die "regeneratio imperii". Das imperium Romanum als "ciuitas terrena" en Unser Geschichtsbild. Wege zu einer universalen Geschichtsbetrachtung (München, Bayerischer Schulbuch-Verlag, 1954) 73-98. Véase tratada esta problemática en MANDOUZE, 298, not. 1; 299, not. 1-2.

34. Cf. M. SeYbold, Zu Augustins "civitas terrena": MThZ 17 (1966) 243-252; MANDouZE, 300 , not. 1-2.

35. Cf. J. Raztzinger, Herkunft und Sinn der Ciuitas-Lehre Augustins. Begegnung und Auseinandersetzung mit Wilhelm Kamlah: AugMag II, 965-979: 972; E. GILson, Les métamorphoses, 37; MANDOUZE, 300, not. 2; 312, not. 4.

36. De ciu. Dei XV, 1 (CC 48, 453).

37. De ciu. Dei XIV, 1 (CC 48, 414). 
Descártese de la mística locución agustiniana, por favor, cualquier asomo de análisis en el plano sociológico o político, por más que el adverbio mystice afecte a las dos ciudades por igual. Cuando Agustín de Hipona escribe de los ciudadanos de la república terrestre, piensa en los miembros de un pueblo o de un Estado, sí, pero ni pueblo ni Estado son condenados como tales, sino porque, al poner sus miras sobre la tierra, hacen suyas las leyes de la diabólica ciudad. Son malos por quererse terrenos de modo exclusivo, lo que basta para quedar fuera de la ciudad de Dios. Ciudadanos un día definitivamente de Jerusalén o de Babilonia, el hombre lo es ya con carácter provisional, inestable, de una u otra. Desde el punto de vista agustiniano, pues, ciudad terrena quiere decir ciudad de los hijos de la tierra, sociedad cuyos miembros, ligados por vínculo de amor exclusivo a las cosas de la tierra, reputan a ésta por su única y verdadera ciudad ${ }^{38}$.

\section{Ciuitas terrena spiritualis-Tertium quid}

El oscuro asunto de las relaciones obliga a seguir matizando. En teoría no es difícil establecer un neto dualismo entre ambas ciudades. Pero bajando al desarrollo concreto de los cometidos específicos, la cosa cambia. La oposición es tal que algunos estudiosos han llegado a proponer una tercera en discordia ${ }^{39}$. Hay quien la ha calificado de ciuitas terrena spiritualis, es decir, ciudad secular no más pecaminosa e idolatrada sino intrínsecamente cristianizada; sociedad temporal iluminada por ideales espirituales ${ }^{40}$; estado en el que, salvadas siempre la independencia y soberanía en el gobierno temporal, sus manifestaciones de la vida pública y privada están penetradas de espíritu cristiano ${ }^{41}$; estado terreno, en suma, que, pese a permanecer tal, busca como meta propia el trascenderse hacia Dios ${ }^{42}$.

Una interpretación así me parece poco menos que imposible. Porque elevar una realidad meramente secular -el Estado- a la dimensión siempre

38. E. GILSON, Les métamorphoses, 55; MANDOUZE, 301, not. 1-2.

39. El rechazo de un planteamiento fundamentalmente dualista condujo a proponer en la doctrina agustiniana una tripartición implícita de ciudades que, según Leisegang, por ejemplo, vendría a ser como una jerarquía de inspiración platónica. Contra la opinión de Leisegang, opinan E. Granz y E. Meuthen. Véase estudiada la problemática en MANDouze, 302, not. 2; y en P. BORGOMEO, 300-307.

40. Cf. P. BrezzI, Una "Civitas terrena spiritualis" come ideale storico-politico di Sant'Agostino: AugMag II, 915-922.

41. Cf. P. BrezzI, Analisi ed interpretazione del "De Civitate Dei" di S. Agostino (Tolentino 1960) p. 70.

42. Cf. H. Hendrikx, Die Bedeutung von Augustinus "De Civitate Dei" für Kirche und Staat: Aug. 1 (1961) 79-93: 89. 
sacral de un reino de Dios, por muy provisional que ese reino sea, equivale a no distinguir entre la Iglesia y el Estado, y a conceder a la estructura política fines escatológicos propios de la Iglesia. La expresión ciuitas terrena spiritualis resulta, por eso, "un monstruo verbal que hace saltar las categorías agustinianas" ${ }^{43}$.

Por su parte, Ch. Journet habló de ciudad del hombre, y fue cuando Marrou reaccionó en Oxford con su resonante conferencia del Tertium quid ${ }^{44}$ : entre ambas ciudades hay, al menos, una cosa diferente, llámese le donné empirique de l'histoire, o simplemente, -propuso el agustinólogo francéssaeculum, entre cuyas posibles traducciones está la de tiempo de la historia. Hizo fortuna esta palabra entre los especialistas, aunque el análisis no pasara del plano histórico ${ }^{45}$.

Interpretado saeculum en sentido de historia, se hace imposible que Tertium quid sea realidad del mismo orden que las dos ciudades. No hay, pues, tercera ciudad. Ahora bien, entre la de Dios, identificada en esperanza - no en realidad - con la Iglesia presente, y la del diablo, identificada - de hecho, pero no de derecho- con la del hombre, existe un Tertium quid, que sería la ciuitas Dei permixta, en situación de espera; sencillamente: la Ecclesia qualis nunc est ${ }^{46}$.

\section{Vivir en Babilonia-ser de Babilonia}

Lo mismo Roma que el Estado pueden llamarse ciudad terrena, mas no del diablo. Durante la historia pagana, la ciudad terrena no admitía esta dicotomía conceptual. Después de Cristo, sí podemos distinguir entre la ciudad

43. H.-I. Marrou, La théologie de l'histoire: AugMag III, 193-204: 201. Véase por esta misma dirección, J. C. GuY, Unité et structure logique de la "Cité de Dieu" de saint Augustin (Paris 1961) p. 120s.

44. Ch. Journet, , Les trois Cités: celle de Dieu, celle de l'homme, celle du diable: Nova et Vetera 33 (1958) 25-48; Id., L'Église du Verbe incarné, II, 21-33; y III (1969) 63-78. En contra de Journet, cf. E. GILson, Eglise et Cité de Dieu chez saint Augustin: Archives d'histoire doctrinale et littéraire au Moyen Âge 20 (1953) 5-23: 19. Y sobre todo, H:-I. MARrou, "Civitas Dei, civitas terrena: num tertium quid? ": SP 2 (Berlin 1957) 342-350, artículo recogido en Christiana tempora. École française de Rome (Roma 1978) p. 418s. Véanse, estudiando la cuestión, FolGADO, 78; MANDOUZE, 302; BoRGOMEO, 300-307: 302s; y especialmente, con fino estudio, A.-M. LA Bonnardière, La "Cité terrestre" d'après H.-I. Marrou, en Saint Augustin et la Bible, 387-398.

45. Cf. L. Verheijen, "Mundus" et "Saeculum" dans les "Confessions" de saint Augustin, en Studi in onore di A. Pincherle (Roma 1967) p. 665-682; R.A.MARKUs, Saeculum. History and Society in the Theology of Saint Augustine, Cambridge University Press (London 1970); G. MADEC, Compte rendu de R.A. Markus, "Saeculum:: REAug 17 (1971) 383-387; A.-M. LA BoNNARDIÈRE, La "Cité terrestre" d'après H.-I. Marrou, 396s.; G. LETTIERI, Il senso della storia in Agostino d'Ippona (Roma 1988), espec. Appendice 1. Lo stato cristianizzato tra "civitas Dei" $e$ "civitas terrena", p. 197-204.

46. Cf. P. Borgomeo, 307. Véase, además, la nota 32. 
terrena diabólica, que continúa congregando a los réprobos, e histórica, visible, secular, identificable con el Estado ${ }^{47}$. Babilonia, pues, encierra dos acepciones: la primaria, ciudad del diablo, y la secundaria, ciudad temporal, o Estado. En la segunda se trata de una realidad secular y dolorosa por ser lugar de exilio para los ciudadanos de Dios, pero ya no es más la pecaminosa y demoníaca. Igual que los cristianos viven en el mundo sin ser del mundo, sin absolutizarlo, colaboran y trabajan en Babilonia - vida política del Estado secular- sin absolutizar su incumbencia. Son capaces incluso de actuar en la vida política de manera más honesta y fructuosa que los paganos. Estar en Babilonia no significa necesariamente ser de Babilonia ${ }^{48}$.

San Agustín llega incluso a teorizar sobre una república terrena favorable a las influencias de la religión y de la ética. La imposibilidad de identificar la ciudad de Dios con un imperio cristiano tampoco le impide reconocer que pueda darse un imperio cristianizado, libre de la opresión y de las turbiedades de la diabólica ciudad, abierto de algún modo, por consiguiente, al influjo y, en parte, realización de los ideales cristianos ${ }^{49}$. En resumen, los cristianos viven materialmente en el exilio de la ciudad del hombre ${ }^{50}$, sin tomar parte espiritual en ella ${ }^{51}$. Lo cual significa que los hijos de la Iglesia pueden atender los negocios de là ciudad del hombre ${ }^{52}$, disfrutar la paz de este siglo y contribuir a su administración ${ }^{53}$ sin ser, por ello, de la ciudad del hombre.

\section{CONVERGENCIAS}

Radicalmente enfrentadas, ambas ciudades comparten, sin embargo, uso y disfrute de los bienes comunes, necesarios en la vida temporal. Debe reinar entre una y otra, por consiguiente, la armonía de las convergencias. $\mathrm{Y}$ así lo deja entender nuestro autor en De uera religione cuando del hombre nuevo y celestial afirma que ha de convivir forzosamente con el viejo hasta la muerte ${ }^{54}$.

47. Así lo entendió Ratzinger en su tesis doctoral (Volk und Haus Gottes in Augustins Lehre von der Kirche, München, Zink, 1954) refiriéndose particularmente a In Ps. 26, s. 2,18; 51, 3-4-6; 61, 5-9. Véase, S. CotTA, Introduzione generale a la Cittá di Dio: Politica (Roma, Città Nuova, 1978) p. CXXXI-CLII; P. BORGOMEO, 305-307; G. LETTIERI, 197s.

48. Cf. In Ps. 136; 61,8. G. LeTTIERI, 198 .

49. Cf. F.-J. ThONNARD, not. comp. 18. Le problème de l'État chrétien: BA 37 (Desclée de Brouwer 1960) p. 748-752; S. D'ELIA, Storia e teologia della storia nel De Civitate Dei, en La storiografia eclesiastica nella tarda antichità (Messina 1980) p. 391-481: 451; G. LETTIERI, 198s.

50. Cf. In Ps. 64, 3; De ciu. Dei XVIII, 1.

51. Cf. In Ps. $64,3$.

52. Cf. In Ps. 51, 6.

53. Cf. De ciu. Dei XIX, 17.

54. Cf. De u. rel. 27,50 (CC 32, 219; BAC 30/IV, p. 131). 
Juntas caminaron desde su nacimiento y juntas quiere Agustín que vayan por su inmortal obra ${ }^{55}$. Tuvieron asiento en los ángeles y ahora pasan la vida buscando afanosamente intereses respectivos ${ }^{56}$. Corporalmente mezcladas y espiritualmente separadas a la vez, comparten las categorías del espacio y del tiempo en modo tal que los hombres de la celeste son, en apariencia, iguales que los de la terrestre: "como ellos nacen, comen, beben, se visten, pasan esta vida" 57.

La paz temporal es el ápice de tales convergencias. La ciudad de Dios busca la única que merece dicho nombre ${ }^{58}$, pero acontece que "Babilonia también tiene sus propios amadores, que atienden a la paz temporal y, no esperando otra cosa, cifran y circunscriben todo su gozo en esto, y les vemos asimismo trabajar sobremanera en pro de la terrena república" ${ }^{59}$. Hasta cooperan unos y otros a una paz así desde posiciones intercambiadas: "Debido a la mezcla temporal — precisa nuestro doctor de la paz-, acontece a veces que algunos que pertenecen a la ciudad de Babilonia administran las cosas de Jerusalén; y, por el contrario, quienes pertenecen a Jerusalén administran los asuntos de Babilonia" ${ }^{60}$. "Los ciudadanos de la ciudad perversa, pues, administran algunos asuntos de la ciudad santa"; y al revés: "toda república terrena tiene por administradores de sus asuntos a (los de la ciudad santa)" 61 .

Corroborado esto con ejemplos de pasada historia, Agustín echa mano de lo que en su tiempo deparaba la casuística de la cosa pública, para exclamar a continuación: "iCuántos fieles, cuántos excelentes magistrados hay en sus ciudades que ocupan los cargos de jueces, de gobernadores, de condes y de reyes!" ${ }^{2}$. Roma y el Estado son parte de la ciudad del hombre, mas no

55. Cf. De ciu. Dei XVIII, 1 (CC 48, 592; BAC 172/XVII, p. 408). Véanse, LaURAs-RonDET, 149; CAPÁNAGA, not. 50 (BAC 172, P. 988s).

56. Cf. De Gen. litt. XI, 15 (CSEL 28/1, 347s). Nota 7.

57. In Ps. 148, 16 (CC 40, 2176; BAC 264/XXII, p. 895); 64,2; 61,6. 8; 136,1; De Gen. litt. $\mathrm{XI}, 15$. Véanse, LAURAS-RONDET, 111s.

58. "Es decir, la convivencia que en perfecto orden y armonía goza de Dios y de la mutua compañía en Dios" (De ciu. Dei XIX, 17: CC 48, 684; BAC 172, p. 603). Sobre la pax temporalis trata san Agustín larga y profundamente en De ciu. Dei XIX. En el curso 1947-1948, Marrou calificó de tractatus de pace los párrafos 11 al 20 del libro XIX del De ciu. Dei (cf. A.-M. LA. Bonnardière, La Bible dans la "Cité de Dieu", 393). Para la paz según san Agustín y en ambiente antidonatista, véanse Y. ConGAR, not. compl. 1. "Pax" chez saint Augustin: BA 28, p. 711-713; P. LANGA: BAC 498, p. 178, not. 2.

59. In Ps. 136, 2 (CC 40, 1964; BAC 264/XXII, p. 592).

60. In Ps. 61,8 (CC 39,778 ; BAC $246 / X X$ p. 542 ).

61. In Ps. 61, 8 (CC 39, 779; BAC 264/XX p. 542).

62. In Ps. 61, 8 (CC 39, 779; BAC 264/XX p. 542). In Ps. 51,6: "Ahora pongamos la mirada en un ciudadano de Jerusalén, en un ciudadano del reino de los cielos que administra algún negocio terreno. Imagínate que es togado, magistrado, edil, procóncul, emperador, gobernante de la república terrena; si es cristiano, si es fiel, si es piadoso, si desprecia las cosas en que se halla y espera las que aún no posee, tiene su corazón puesto en el cielo" (CC 39, 627; BAC 264, p. 279). 
son toda la ciudad del hombre. Sus posibles concordancias atañen sobre todo al gobierno de la república, al ejercicio de la cosa pública, y en esa dirección habrá que apuntar con lo antedicho de la paz temporal, sin que tampoco implique decir que es tarea sólo de estadistas y políticos, o de organismos internacionales de carácter civil o religioso. Bien claro está que deben promoverla cuantos integren la ciudad terrestre, el hombre de a pie comprendido: "Cualquiera que se ocupe lealmente (en trabajar a favor de la terrena república), y si allí no va en busca de la soberbia, y de la exaltación perecedera, y de la repugnante petulancia, sino que muestra verdadera solicitud -la que puede, mientras puede ${ }_{2}$ con quienes puede- por las cosas terrenas y se dedica - en cuanto puede - a lo que pertenece a la hermosura de la ciudad, Dios no le deja perecer en Babilonia, pues le predestinó para ser ciudadano de Jerusalén". 63 .

La parte de la ciudad de Dios llamada Iglesia peregrina también necesita la buena administración y el mantenimiento de la vida transitoria y la paz temporal, patrimonio común de ambas ciudades ${ }^{64}$. Utiliza las realidades temporales de la tierra, en ellas procura apoyarse, obedece las leyes de aquí abajo, "conserva y favorece todo aquello que, diverso en los distintos países, se ordena al único y común fin de la paz en la tierra" ${ }^{65}$, y sin preocuparse de su disparidad de costumbres, leyes o estructuras, pues "nada les suprime, nada les destruye" 66 .

"El uso de las cosas indispensables para la vida mortal es común a estas dos clases de hombres y de familias. Lo totalmente diverso es el fin que cada uno se propone en tal uso. De este modo la ciudad terrena, que no vive precisamente según la fe, aspira a la paz terrena, y hace que la bien ordenada armonía del mando y de la obediencia de sus ciudadanos estribe en un equilibrio de las voluntades humanas con respecto a los asuntos propios de la vida mortal" 67 .

\section{TENSIONES}

La ley de los contrarios o dialéctica de los dos amores predomina sobre las convergencias. El texto es clásico de puro repetido: "dos amores dieron origen a dos ciudades: el amor de sí mismo hasta el desprecio de Dios, la

63. In Ps. 136, 2 (CC 40 1964s.; BAC 264/XII p. 529s.).

64. Cf. De ciu. Dei XIX, 17 (CC 48, 684; BAC 172/XVII, p. 600). Véanse, LAURAS-RoNDET, 150 .

65. Cf. De ciu. Dei XIX, 17 (CC 48, 685; BAC 172, p. 602).

66. Cf. De ciu. Dei XIX, 17 (CC 48, 685; BAC 172, p. 602).

67. Cf. De ciu. Dei XIX, 17 (CC 48, 684; BAC 172, p. 600). 
terrena; y el amor de Dios hasta el desprecio de sí, la celestial. La primera se gloría en sí misma; la segunda en el Señor. Aquélla solicita de los hombres la gloria; la mayor gloria de ésta se cifra en tener a Dios como testigo de su conciencia" ${ }^{68}$.

Más extenso y pormenorizado aún De gen. litt. XI,15,20: "Estos dos amores de los cuales uno es santo y el otro impuro, el uno social, el otro privado; el uno que busca la utilidad común para conseguir la celestial compañía; el otro que encauza, por el arrogante deseo de dominar, el bien común en provecho propio; el uno sometido a Dios, el otro en pugna con Él, tranquilo el uno, alborotado el otro; pacífico uno, sedicioso otro; el uno que prefiere la verdad a las alabanzas de los que yerran, el otro que está ávido de cualquier clase de honores; caritativo el uno, envidioso el otro; el uno que desea para el prójimo lo que para sí, el otro que ansía someter al prójimo a sí; el uno que gobierna al prójimo para utilidad del mismo prójimo, el otro para utilidad propia; tuvieron su asiento en los ángeles, en los buenos uno y en los malos otro, (y se diferenciaron) bajo la admirable e inefable providencia de Dios, que ordena y gobierna todas las cosas creadas, las dos ciudades creadas en medio del género humano; la una de los justos, de los pecadores la otra; las cuales, entremezcladas ahora temporalmente, transcurren la vida del mundo hasta que sean separadas en el último día del juicio" ${ }^{69}$. Común el uso, diverso el fin que en tal uso cada uno se propone ${ }^{70}$.

Agustín de Hipona reafirma penetrante el hecho, la duración, la intensidad y el final escatológico del conflicto ${ }^{71}$. Con bien definido nombre una y otra ${ }^{72}$, en el fondo existe verdaderamente como ciudad sólo la de Dios, ya que sólo ella goza del íntimo lazo de la caridad, cuyo fuego "ningún vaivén del mundo, ninguna avenida de la tentación extinguirá" ${ }^{73}$. Babilonia, en cambio, más que diabólica ciudad es la anti-ciudad de Dios, en su seno desgarrada, sin más signo que el del rechazo, sin otro final que el de la perdición.

No se interprete al Hiponense aquí náufrago perdido del dualismo maniqueo, como si dichas ciudades fuesen dos principios eternos. Considéresele, más bien, inteligente y tranquilo navegante del bíblico, refiriéndose a la opo-

68. Cf. De ciu. Dei XIV, 28 (CC 48, 451; BAC 172, p. 137); cf. XVIII, 1; Retract. II, 43,2; CAPÁNAGA: BAC 171, p. 116-119; 98s.; TRAPE, Introduzione, p. LXVI. Sobre el amor en san Agustín, cf. D. DIDEBERG, amor: Augustinus-Lexikon (=AL) 1 (Basel-Stuttgart 1986) 294-300.

69. De Gen. litt. XI, 15,20 (CSEL 28/1, 347s; BAC 168/XV, p. 921s.).

70. Además de la nota 67 , cf. In Ps. 36, s.2,1.

71. Cf. In Ps. 51,4; 61,6. 8; 64,2.4; 136,1. BORGOMEO, 306.

72. La ciudad de Dios, Jerusalén; la del diablo, Babilonia. Jerusalén, ciudad de piadosos; Babilonia, de impíos. Cf. In Ps. 26,2,18; 61,6.7; 86,7; 136,20. LAuRAs-Rondet, 123s.

73. In Ps. 47,13 (BAC 246/XX, p. 154). BORGOMEO, 301s. 
sición moral y religiosa entre dos familias espirituales ${ }^{74}$. Por seguir los derroteros de la brevedad, reduciré las muchas y frecuentes colisiones que entre ambas ciudades se dan a estos cinco títulos panorámicos: humildad y soberbia, caridad y concupiscencia, sabiduría y estulticia, verdad y vanidad, vida según el espíritu y vida según la carne.

\section{$1^{\text {a }}$ Humildad y soberbia}

Si la primera es agradable flor de la ciudad de Dios, la segunda es agresivo espino de la del diablo. Aunque esclavos de la terrena, los hombres de la celestial gozan y sienten la verdadera libertad en el corazón. Los de la terrestre, por el contrario, libres en apariencia, son, en realidad -admítase o no-, esclavos. Por querer adueñarse del mundo, la de aquí "se ve esclava de su propia ambición" 75 . Humildad y soberbia definen en dos palabras a las dos ciudades, precisamente por ser distintivos de sus dos reyes: Cristo y el diablo. "Del (pecado primero) viene el que ahora, en este mundo de peregrinación, se recomiende, sobre todo a la ciudad de Dios, la humildad y se proclame de especial modo en Cristo, su rey. Se nos enseña en las Sagradas Letras que el vicio de la soberbia, contrario a esa virtud, domina mayormente en su adversario el diablo. Ésta es, sin duda, la gran diferencia entre las dos ciudades de que hablamos" ${ }^{76}$. Y por supuesto que ésta es también la de sus hombres ${ }^{77}$, con inclinaciones propias cada uno: "los justos esforzándose en tender a las cosas sublimes por la humildad, los inicuos inclinándose a las abyectas por la altanería. Los primeros se anonadan para subir; los segundos se pavonean para caer. De aquí acontece que unos toleran y otros son tolerados. El designio de los justos es ganar a los inicuos para la vida eterna, y el de los perversos devolver mal por bien y privar, si fuese posible, aun de la vida temporal a los que buscan para sí la vida eterna" ${ }^{78}$.

74. Aventajado alumno de las Escrituras Sagradas, Agustín de Hipona podía recordar fácilmente las oposiciones que san Juan pinta entre luz y tinieblas, entre Cristo, rey de la ciudad celeste, y el diablo, príncipe de este mundo. Dígase lo mismo de la antítesis paulina entre antiguo y nuevo Adán, o de la interpretación alegórica de la historia protagonizada por Sara y Agar. Véanse, LAURAS-RONDET, 152; TRAPE, Introduzione, p. XXIV-XXIX.

75. De ciu. Dei I, pról.: "ipsa ei dominandi libido dominatur" (CC 47,1; BAC 171, p. 4). Al respecto, véanse O. SCHAFFnER, Christliche Demut, des hl. Augustinus Lehre von der Humilitas, Cass. 7 (Würzburg 1959); D.J. MACQUeEN, Augustine on Superbia. the historical Background and Sources of his Doctrine: MSR 34 (1977) 193-211.

76. De ciu. Dei XIV, 13 (CC 48, 435; BAC 171, p. 103s.); cf. X, 28; 29,2. TRAPE, Introduzione, p. LXVIIIs.

77. Cf. De ciu. Dei XIV, 13.

78. In Ps. 36, s. 2,1 (BAC 235/XIX, p. 593). 
$2^{\mathrm{a}}$ Caridad y concupiscencia (ambición)

La celéberrima frase agustiniana del pondus meum amor meus; eo feror, quocumque feror ${ }^{79}$ es ideal para explicar que las pasiones humanas pueden reducirse todas al amor. Serán buenas o malas si el amor es bueno o malo, y éste una cosa u otra según se acomode o no al orden de las cosas, dependiente, a su vez, de la ley eterna ${ }^{80}$. Lo común es que Agustín escriba, en este argumento, amor de Dios / amor de sí para indicar la oposición que enfrenta a las dos ciudades, pero tampoco falta el texto donde recurre a la no menos sugeridora y profunda expresión de amor social / amor privado ${ }^{81}$. ¿Qué alcance agustiniano podemos dar a estos términos? Amor social quiere decir amor del bien común; amor privado, por contra, amor deseado y poseído excluyendo a los demás. El social, une. El privado, divide. Llámasele privado porque, a quien lo posee -o de él es poseído, diríase mejor- le priva de la comunión con Dios y con los hombres. Amor social quiere decir, por consiguiente amor de Dios y amor de uno mismo y de los otros, pero en Dios, que es el supremo bien común ${ }^{82}$. Fuerza de atracción y de unidad de la vida social, ese bien común que es Dios y sus divinas perfecciones de las que los santos participan, explica que el método del amor social consista, básicamente, en imitar la vida social de los santos, prefiriendo lo común a lo propio. En lo íntimo y propio radica, en cambio, el amor privado, fuente del egoísmo, y causa por tanto de las divisiones, los vicios y la guerra. El amor privado colisiona con el social y origina un desorden. En la ciudad de Dios escatológica sólo reinará el amor social ${ }^{83}$.

\section{$3^{\text {a }}$ Sabiduría y estulticia}

La ciudad terrena se gloría en sí misma; la del cielo, en el Señor: illa in se ipsa, haec in Domino gloriatur ${ }^{84}$. "Por eso, los sabios de aquélla, viviendo según el hombre, han buscado los bienes de su cuerpo o de su espíritu o los de ambos; y pudiendo conocer a Dios, no le honraron ni le dieron gracias

79. Conf. XIII, 9,10 (CC 27,246s); Cf. De ciu. Dei XI, 28. A. TrAPE, Introduzione, p. LXVII; G. MADEC, La Patrie et la Voie. Le Christ dans la vie et la pensée de saint Augustin (Paris 1989) 299s.

80. Cf. De ciu. Dei XIV, 7; De d.chr. I, 27,38; C. Faust. XXII, 27.

81. Véase la nota 69. También A. TRAPÈ, Il principio fondamentale della spiritualità agostiniana, en Sanctus Augustinus vitae spiritualis magister, I (Roma 1959) p. 1-41.

82. Cf. De ciu. Dei XII, 9 (CC 48, 364; BAC 171, p. 772). A. TrAPÈ, Introduzione, p. LXVII; Id., S. Agostino. L'uomo, il pastore, il mistico, 316; Id., Il principio fondamentale della spiritualità agostiniana, $15 \mathrm{ss}$.

83. Cf. Des. D. monte I, 15,41; Ep. 243.

84. De ciu. Dei XIV, 28 (CC 48, 451; BAC 172, p. 137). 
como a Dios, sino que se desvanecieron en sus pensamientos, y su necio corazón se oscureció. Pretendiendo ser sabios, exaltándose en su sabiduría por la soberbia que los dominaba, resultaron unos necios (stulti)" ${ }^{85}$. De modo que si la sabiduría refulge en la ciudad de Dios, la estulticia oscurece en la ciudad del hombre. No hay en el hombre otra sabiduría que la de una vida religiosa, con la que se honra justamente el verdadero Dios, esperando como premio en la sociedad de los santos el triunfo de la ciudad de Dios sobre la ciudad del hombre (cf. 1Co 15,28) ${ }^{86}$. Que la sabiduría quiera lo necio (stultum) es imposible ${ }^{87}$, pues la stultitia uera, est falsa sapientia ${ }^{88}$, y la sabiduría del mundo es necedad ante Dios ${ }^{89}$. El final escatológico de la ciudad de Dios se resuelve en disfrutar la sabiduría con los amigos ${ }^{90}$. Apurando el análisis, percibe uno latente en el discurso la no menos conocida frase agustiniana del frui et $u t i{ }^{91}$, a cuyo mensaje enseña que las cosas temporales se han de usar en función del orden superior al que apuntan, y que el disfrute mira, más bien, a las eternas. "Los buenos, ciertamente, usan de este mundo para gozar de Dios; los malos, al contrario, quieren usar de Dios para gozar del mundo" 92 .

\section{$4^{\mathrm{a}}$ Verdad y vanidad}

"Difieren entre sí por oposición" ${ }^{93}$, y se oponen como lo duradero a lo efímero, como el ser a la nada. A la vanidad objetiva de las cosas responde la subjetiva de los hombres. El hombre, hecho para la verdad, cayó por el pecado en poder de la vanidad, se hizo mortal, hijo del "tiempo que se desliza y

85. De ciu. Dei XIV, 28 (=Rom 1,21-25): G. MADEC, Connaisance de Dieu et action de grâces. Essai sur les citations de Epître aux Romains 1,18-25 dans l'oeuvre de saint Augustin: RechAug 2 (1962) 273-309; W. STEIN, Sapientia bei Augustinus, diss. (Köln 1973).

86. Cf. De ciu. Dei XIV, 28. Sobre societas sanctorum, véase P. LANGA: BAC 498, p. 136s.

87. Serm 214,4: "Non enim potest iustitia uelle facere quod iniustum est, aut sapientia uelle quod stultum est, aut ueritas uelle quod falsum est" (PL 38, 1068; BAC 447/XXIV, p. 167).

88. Serm. 150,9 (PL 38, 813; BAC 443/XXIII, p. 374).

89. Cf. Serm. 240,5 (PL 38, 1132; BAC 447, p. 455).

90. Cf. Denis 16,7=Serm. 299 D, 7 (PL 46,873; BAC 448/XXV, p. 348).

91. Cf. F. CAYré, Frui et uti (Augustinus): BA 11 (Desclée de Brouwer 1949) p. 558-561; A. DI GiovanNi, La dialettica dell'amore. "Uti-frui" nelle preconfessioni di Sant'Agostino, Itinerari critici 5 (Roma 1965); G. PfligersdorfFer, $Z u$ den Grundlagen des augustinischen Begriffspaars "uti-frui": WSt 84 (1971) 195-224; más bibl. en H.J. SIEBEN, Voces, 296. Asimismo, P. LANGA, Usar y compartir los bienes según san Agustín: RA 29 (1988) 501-545: 524s.

92. De ciu. Dei XV, 7 (CC 48, 461; BAC 172, p. 154); cf. De d. chr. I, 4-6. CAPÁNAGA: BAC 172 , p. 154 , not. 5 .

93. In Ps. 118, s. 12,1: "A contrario differunt inter se uanitas et ueritas" (CC 40, 1700; BAC 264, p. 72). Véanse, L. Chevallier, H. Rondet, L'idée de "vanité" dans l'oeuvre de saint Augustin: REAug 3 (1957) 221-234; LAURAS-RONDET, 153, not. 148. 
pasa" ${ }^{94}$. Amante de la mentira y de la vanidad, el hombre desde entonces se va en pos de lo accesorio y perecedero, y antepone casi por principio lo secundario a lo principal ${ }^{95}$. Pero esto no es todo: como consecuencia del pecado, es el hombre mismo quien se ha convertido en uanitas uanitatum (Eccl. 1,2) ${ }^{96}$, hasta el punto de no tener, de suyo, otra cosa que pecado, mentira y vanidad. Y "si el que dice mentira habla de lo suyo, el que dice verdad habla de lo que tiene de Dios" ${ }^{97}$. Sólo quien es la Verdad encarnada para conducirnos a la verdad total podía librar al hombre de la esclavitud de la vanidad. Y así lo hizo, de manera radical y para siempre. Lo cual no significa, ni mucho menos, que el peligro de ser atrapados otra vez haya desaparecido por completo, desde luego. Mientras el hombre peregrine mortal por la ciudad terrena, que es el feudo propio de la vanidad, correrá el riesgo de sentirse él mismo vanidad. El deseo de alabanza humana, por ejemplo, es uno de los peligros que más fuerte y frecuentemente se deja sentir. Quienes obran por la gloria humana, se dejan arrastrar por la vanidad. Los que se conducen por la gloria de Dios, son hijos de la verdad ${ }^{98}$. Y la verdad es, precisamente, el patrimonio común de la Jerusalén celeste: ubi thesaurus communis est ueritatis ${ }^{99}$.

\section{$5^{\mathrm{a}}$ Vivir según el espíritu y vivir según la carne}

Tal vez sea la antítesis más acariciada de san Agustín, aparte de incluir a las demás. Vivir según el espíritu significa vivir según Dios; vivir según la carne, vivir según el hombre: "cuando el hombre vive según el hombre, y no según Dios, es semejante al diablo" ${ }^{100}$; y ya sabemos de qué ciudad es príncipe el diablo. La realidad es que el hombre ha sido creado "no para vivir según él mismo, sino según su creador" y actuar de otra manera es una mentira (hoc est mendacium) ${ }^{101}$; caer en la vanidad.

94. In Ps. 143, 11 (BAC 264, p. 279).

95. Cf. In Ps. 4,3 (BAC 235/XIX, p. 27).

96. Agustín conoció dos lecturas de este texto: fiándose al principio de los manuscritos latinos leía uanitas uanitantium (vanidad de los hombres vanos); más tarde, con los manuscritos griegos en mano, prefirió uanitas uanitantum (cf. Retract. I, 7,3). CHEVAlLIER-RondET, 221s.

97. In Io. 5,1 (BAC 139/XIII, p. 144). Véase M.-F. BERROUARD, n. compl. 31. "Chacun ne possède de lui-même que mensonge et péché": BA 61, p. $866 \mathrm{~s}$.

98. In Ps. 4,3: "Sólo la Verdad, por la que todas las cosas son verdaderas, hace felices" (BAC. 235, p. 27); cf. In Ps. 118,12,1; De ciu. Dei XI, 2. ChEvallier-RondeT, 233, not. 82; G. MADEC, La Patrie et la Voie, 39, 53, 59, 161s. 298.

99. De ciu. Dei V, 16 (CC 47, 149; BAC 171, p. 336).

100. . De ciu. Dei XIV, 4 (CC 48, 418; BAC 171, p. 336s). TrAPE, Introduzione, p. LXIX; M.F. Berrouard, not. compl. 1: "Animalis homo:: BA 71, p. 837s.; BorgOMEO, 267s.

101. De ciu. Dei XIV, 4 (CC 48, 418; BAC 172, p. 71). 
Vivir según el espíritu, o la verdad, o la ciudad de Dios, es, por tanto, pura exigencia antropológica y requisito del humanismo cristiano, y mensaje de la teología. Vivir según la carne, acatar las consignas de la ciudad del hombre, seguir los dictámenes de Babilonia, será tanto como bloquear la vocación más hermosa y radical del hombre, admirablemente resumida en el inquietum est.cor nostrum, donec requiescat in te ${ }^{102}$; ser víctimas del pecado, la mentira, la vanidad y la finitud, pues Nemo habet de suo nisi mendacium et peccatum (Io. 5,1) ${ }^{103}$.

Dejando por un momento a un lado el discurso moral, y acudiendo al metafísico, cabría decir que el hombre no puede en modo alguno vivir según el hombre, porque significaría hacerlo según su propio límite, con lo que vendría a ser menos de lo que es. Tiene que vivir, por tanto, según el espíritu, o lo que es igual: según la eternidad, la verdad, el amor; en suma, según Dios, ese Dios que es causa del ser, luz del conocer y fuente del querer ${ }^{104}$.

"Busque, pues, el hombre - recomienda san Agustín con su acostumbrado estilo- a Aquél en quien encontramos la seguridad de las cosas, contemple a Aquél en quien todas son ciertas, ame a Aquél en quien tenemos la suprema rectitud" ${ }^{105}$. Busque, contemple, ame: tres verbos de la más alta escuela agustiniana; tres hitos geodésicos en la planimetría espiritual de la ciudad de Dios; tres formidables actitudes para impedir que la ciudad del hombre le arrastre y precipite a uno por los despeñaderos de la carne ${ }^{106}$. Vivir según el espíritu supone conducirse con arreglo al principio de interioridad: noli remanere in te, transcende et te; in illo te pone qui fecit te ${ }^{107}$. Traducido a categorías actuales, implica el asumir como propio ese apasionante programa de la misión divina que la Iglesia tiene con el mundo de todos los

102. Conf. I, 1,1 (CC 27,1). Cf. A. PINCHERLE, "Et inquietum est cor nostrum". Appunti per una lezione agostiniana: Augustinus 13 (1968) (=Strenas Augustinianas p. V. Capánaga oblatas) p. 353-368; L.F. Pizzolato, Il primo libro delle "Confessiones" di Agostino: ai primordi della "confessio", en "Le Confessioni" di Agostino d'Ippona. Libri I-II (Palermo 1984) p. 9-78: 13, not. 20; G. MADEC, La Patrie et la Voie, 300.

103. Este célebre texto fue recogido por el Concilio de Orange (can. 22) y ha sido objeto de numerosas e inútiles discusiones teológicas, dado que no tiene un significdo moral, sino, como el mismo texto indica, metafísico (cf. TrAPE, Introduzione, p. LXIX). Además de la nota 97, véase G. FrITZ, Orange (deuxième concile d'): DThC XI/1 (Paris 1931) 1087-1103: 1098.

104. Cf. De ciu. Dei VIII, 4. TRAPÈ, Introduzione, p. LXIX.

105. De ciu. Dei VIII, 4 (CC 47, 220s; BAC 171, p. 488s).

106. Cf. Serm. 153,9 (BAC 443, p. 410). Sobrentendido el discurso de Rom 8,5-13 (la vida del espíritu y los que caminan según la carne).

107. Serm. 153,9 (PL 38, 830; BAC 443, p. 410s.). Sobre la inmanencia y la transcendencia, y el principio de interioridad, bibliografía incluida, véase Trapè, San Agustín, en Patrología III, 486-489. 
tiempos, y que en esta época de finitud milenaria se hace, si cabe, más urgente que nunca, a saber: "elevar la ciudad terrena a ciudad de Dios" ${ }^{108}$.

\section{EPÍLOGO}

La genial idea de las dos ciudades, de originalidad agustiniana en desarrollo y sistematización, se ha revelado desde siglos atrás extraordinariamente fecunda y en la actualidad se perfila con futuro prometedor, pues incide en los problemas que más hondamente condicionan y preocupan al hombre moderno. El Concilio Vaticano II constató el nacimiento de un nuevo humanismo, y precisó que su nueva cultura debía compaginarse con el cultivo del espíritu ${ }^{109}$. El argumento apenas expuesto revela que tan ardua empresa conseguirá salir adelante a condición de que se centre en Cristo y se ajuste a la normativa de la ciudad de Dios.

Pone asimismo de manifiesto que el cristiano, en marcha hacia la ciudad celeste, ha de buscar y gustar siempre las cosas de arriba, por mucho que las terrenas se interpongan y provoquen tensiones. Sería ocioso ahora, además de interminable, descender a todas las que se dejan sentir con mayor o menor virulencia en el mundo actual: Debajo de los titulares reseñados caben la guerra, el hambre, el racismo, la manipulación del lenguaje, el terrorismo, la esclavitud de mil signos, el abuso de poder tan variado ćomo los colores del arco iris y cien nombres más que yo podría añadir; exponentes típicos de la ciudad terrena, frente a los cuales la Iglesia peregrina lucha cada día procurando que la familia humana, sin condicionamientos de raza o de color, de religiosidad o de geografía, escale los más altos pensamientos de la verdad, del bien y de la belleza, en esa guerra sin cuartel que libran continuamente la libertad y la esclavitud terrena, frente a los cuales la Iglesia peregrina lucha cada día procurando que la familia humana, sin condicionamientos de raza y de color, de religiosidad o de geografía, escale los más altos pensamientos de la verdad, del bien y de la belleza; en esa guerra sin cuartel que libran continuamente la libertad y la esclavitud.

La experiencia que Agustín de Hipona creía tener de la historia y de la humanidad le empujó a creer que la relación entre ambas ciudadeś había de estar, a lo largo de los siglos, hecha más frecuentementè de luchas que de

108. La frase es de Pío XII, que hizo de ella un mensaje permanente, sobre todo el de los últimos años de su pontificado. Pero responde también a la hermosa doctrina del concilio y de los últimos Pontífices, incansables en la promoción de los valores cristianos. Véanse, I. GroRDANI, La due Città (Roma 1961) p. 14; CAPÁNAGA: BAC 171, p. 97s.

109. Cf. GS 55-56 (BAC 252, 345-347). 
colaboración ${ }^{110}$. ¿Pesimista? Realista, más bien. La tentación de identificar la ciudad terrena con la del diablo, aunque fuerte, nunca pudo con él. Podrá reprochársele no haber extraído toda la riqueza que la fórmula contiene, pero de ningún modo que perdiese una vez tan siquiera su admirable equilibrio.

Difícil y ambiguo tema, éste de las dos ciudades, pues comporta ocuparse a fondo de las fuentes, la composición y la exégesis. Pero denso y de ancho respiro a la vez, realista y vertebral, con respuesta a buen número de las más pavorosas interrogaciones que siempre se hizo la mente humana. $\mathrm{Al}$ estudiarlo, san Agustín abordó el drama de la historia con ojos de pensador y de creyente, es decir, con el filósofo y teólogo juntos, como si pretendiese indicar que los problemas de la humanidad, empezando por el teologal del hombre que tanto apasionó a Zubiri, han de ser analizados y resueltos siempre a la luz de la razón y de la fe.

Prof. Dr. Pedro LANGA, OSA

Instituto Patrístico Augustinianum

Roma, 18 de noviembre de 1989

110. Cf. De ciu. Dei XIX, 17. Lauras-Rondet, 159. 